\title{
Multi-stAGE FLEXIBLE EXPANSION CO-PLANNING UNDER UNCERTAINTIES IN A COMBINED ELECTRICITY AND GAS MARKET
}

\author{
JING QIU \\ B.E. \\ M.Sc.
}

A thesis submitted in partial fulfillment

of the requirements for the degree of

Doctor of Philosophy

The UNIVERSITY
of NEWCASTLE

June, 2014 



\section{DECLARATION}

This thesis contains no material which has been accepted for the award of any other degree or diploma in any university or other tertiary institution and, to the best of my knowledge and belief, contains no material previously published or written by another person, except where due reference has been made in the text. I give consent to this copy of my thesis, when deposited in the University Library, being made available for loan and photocopying subject to the provisions of the Copyright Act 1968.

I hereby certify that the work embodied in this thesis contains published chapters/scholarly work of which I am a joint author. I have included as part of the thesis a written statement, endorsed by my supervisor, attesting to my contribution to the joint publications/scholarly work.

Author:

Jing Qiu

June, 2014

Approved by Principle Supervisor:

Prof. Zhao Yang Dong

June, 2014 

To all my family 



\section{ACKNOWLEDGEMENTS}

My Ph.D. research experience in Australia was like an amazing journey. There were plenty of wonderful and memorable stories along the journey. Every day in the journey was full of happiness, surprise and achievement. This thesis becomes an important milestone in my life, marking the completion of my Ph.D. study journey and the new start of my academic career. I would like to take this precious chance to express my deepest gratitude to those who helped and supported me during my research.

Firstly, I am truly grateful to my principle supervisor, Prof. ZhaoYang Dong. Meeting him has totally changed my entire life. It is the luckiest thing to work under his supervision. His character, wisdom and leadership have positively influenced my personal development. His continuous help, support, and guidance have been very helpful for my research. Meanwhile, I also deeply thank my co-supervisor, Prof. Yusheng Xue, from the State Grid Electric Power Research Institute, China. Prof. Xue has helped and taught me a lot for my research with his vast experience in both research and engineering practices. Working with him was also a very happy experience and with lots of gains.

Secondly, I also appreciate my colleagues, Dr. Junhua Zhao, Dr. Ke Meng, Dr. Yan Xu, Dr. Fengji Luo, Mr. Yu Zheng, and Dr. Yingying Chen. I had the pleasure of working with them. Their help and contribution are essential parts for the completion of this thesis.

Thirdly, I express many thanks to the Australian federal government, the University of Queensland and the University of Newcastle. The commonwealth supported full scholarships, International Postgraduate Research Scholarship (IPRS), Australian Postgraduate Award (APA) and University of Queensland Centennial scholarship (UQCent) provided great financial supports for my study in Australia.

Last but not least, I would like to thank my family, especially my parents and grandparents. Their love and support is a solid base when I am pursuing my dream. My special thanks go to 
my dear wife, Huiqiao Tian. Her sacrifice and support is the strongest motive for me to strive for goals. 


\section{TABLE OF CONTENTS}

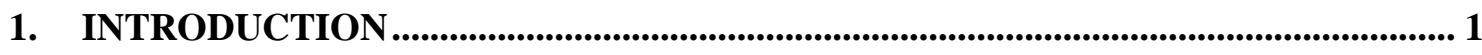

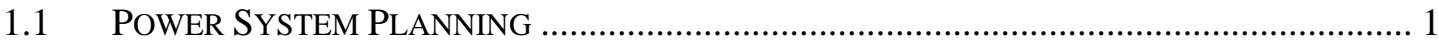

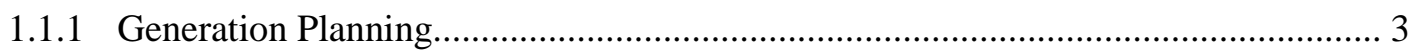

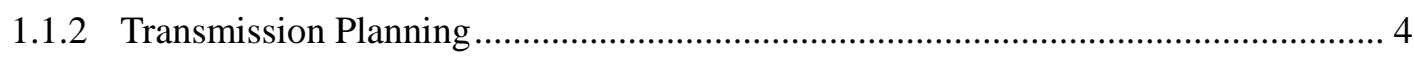

1.2 RELIABILITY CRITERION FOR POWER SYSTEM PLANNING ........................................... 4

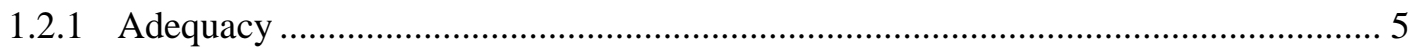

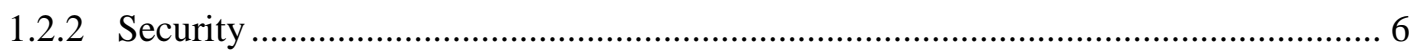

1.3 POWER SYSTEM PLANNING IN A NEW ENVIRONMENT …............................................. 7

1.4 FUEL SUPPLY, POWER GENERATION AND TRANSMISSION............................................. 9

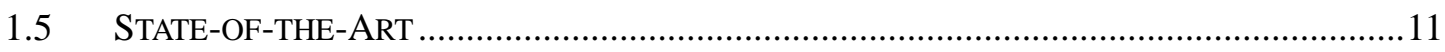

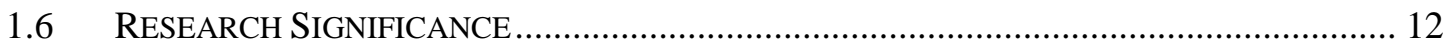

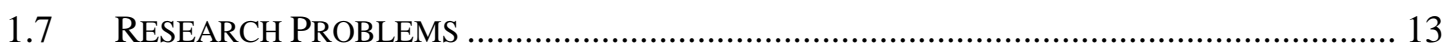

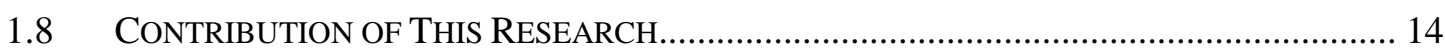

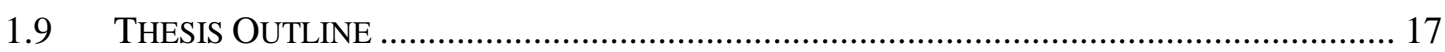

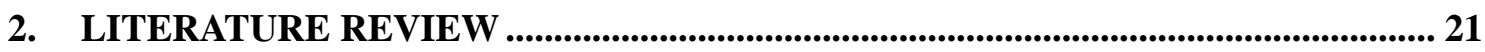

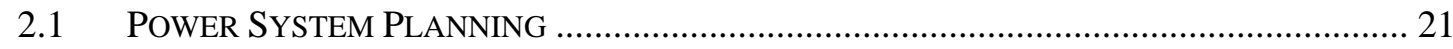

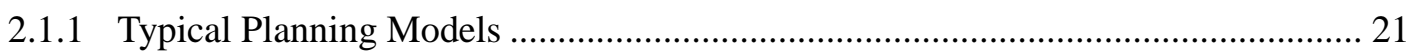

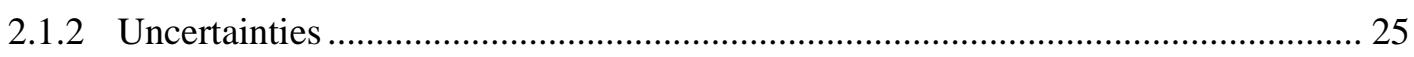

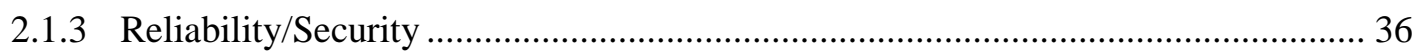

2.1.4 Deregulated Electricity Market........................................................................... 42

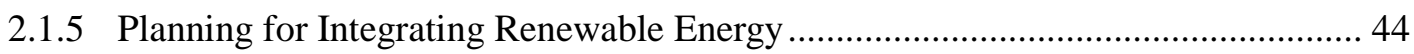

2.1.6 Coordinated Generation and Transmission Planning............................................... 45

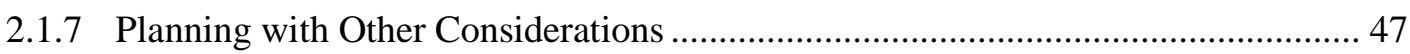

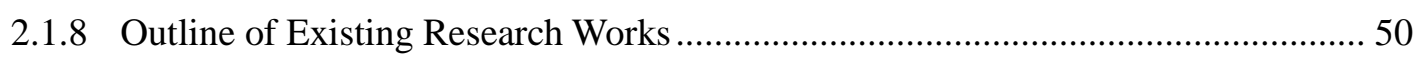

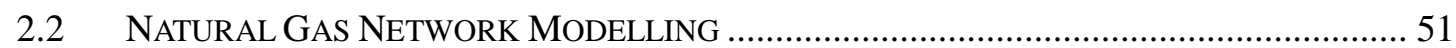

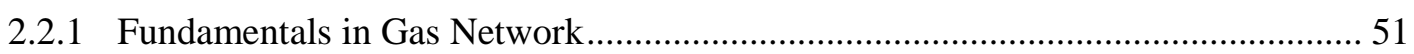

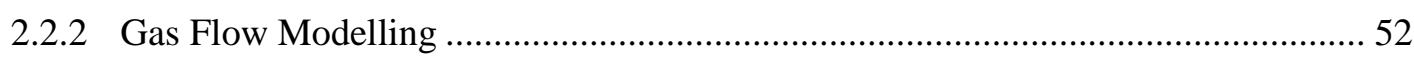

2.2.3 Compressor Station Modelling ………………..................................................... 54

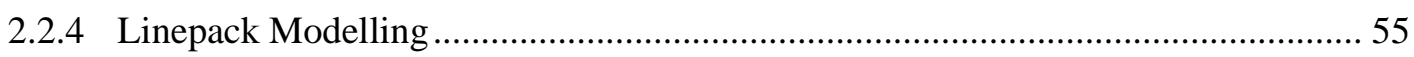

2.2.5 Linear Gas Flow Modelling in Markets.................................................................. 56

2.3 JOINT PLANNING OF GAS AND POWER SYSTEMS ....................................................... 59

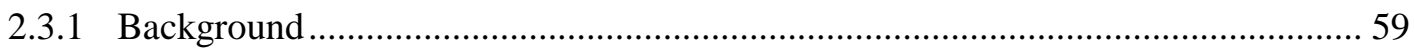

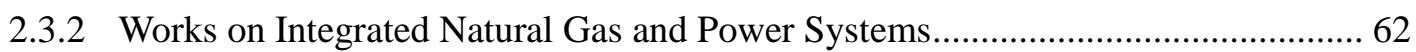

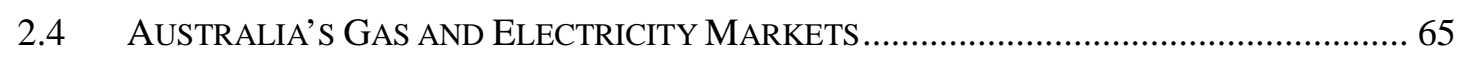

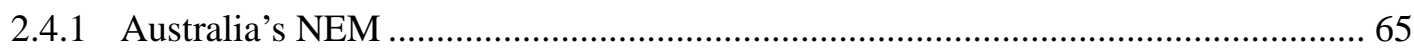

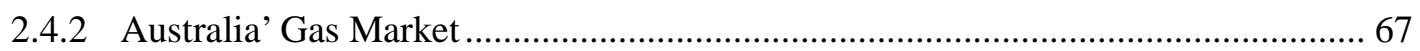

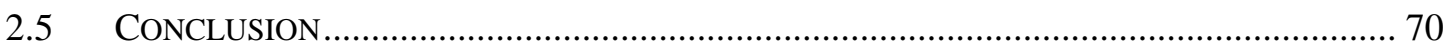

3. GENERALIZED RELIABILITY FOR INTEGRATED GAS AND POWER 


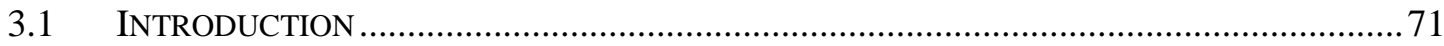

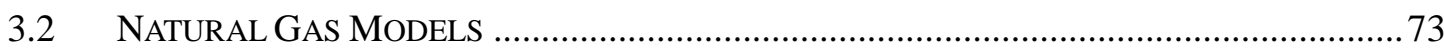

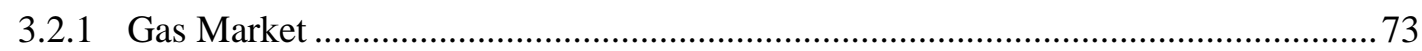

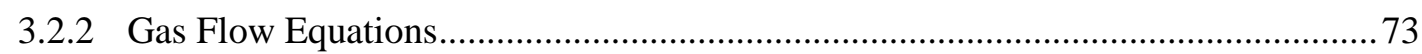

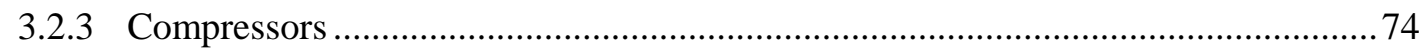

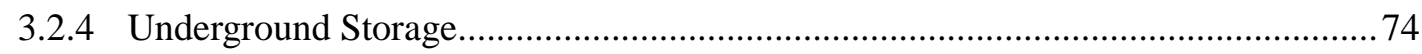

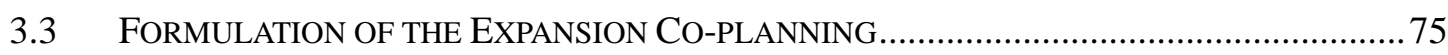

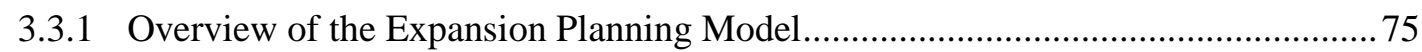

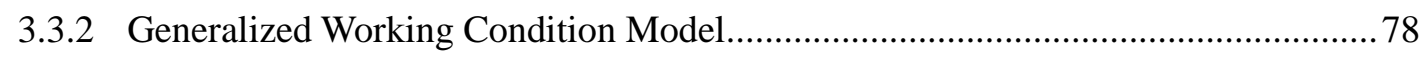

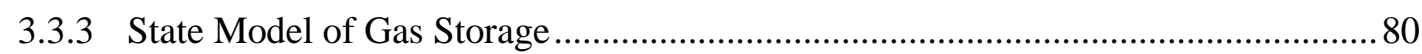

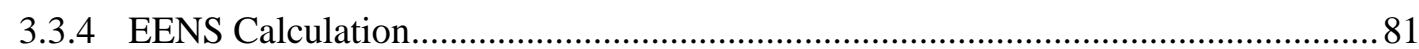

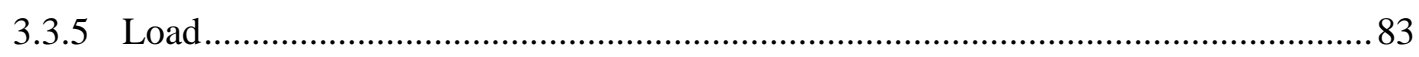

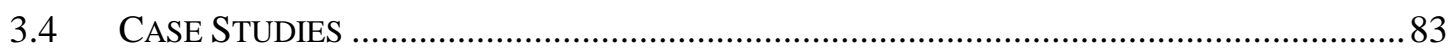

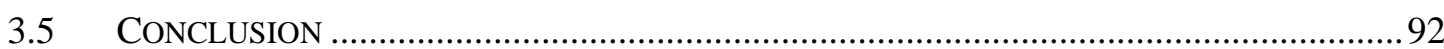

4. PLANNING IN A COMBINED ENERGY MARKET CONSIDERING MARKET

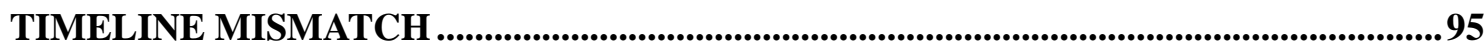

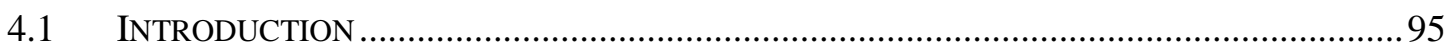

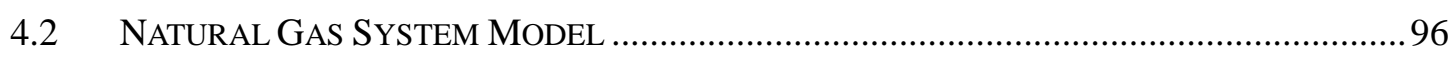

4.2.1 Overview of the Gas Network Model......................................................................96

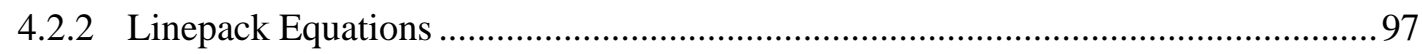

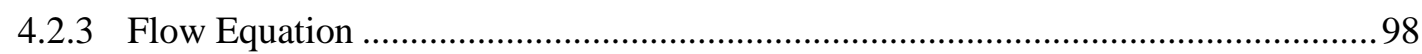

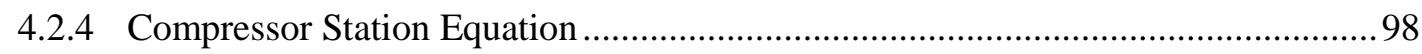

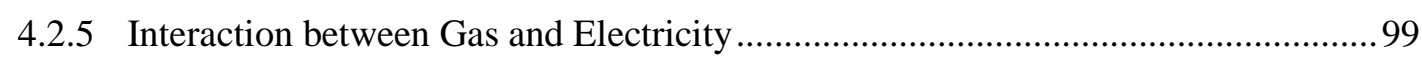

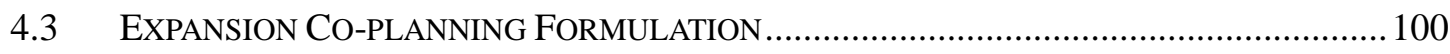

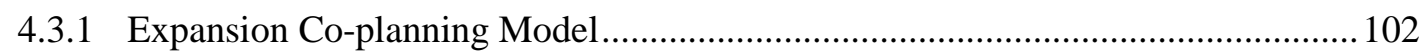

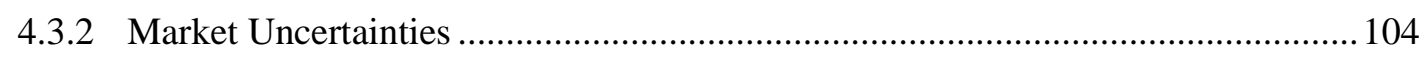

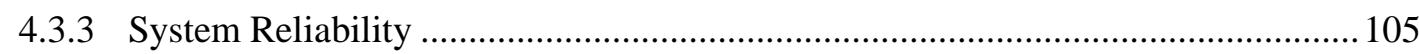

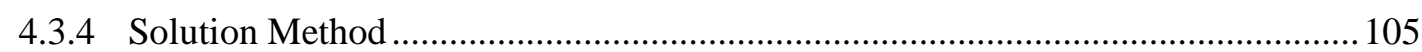

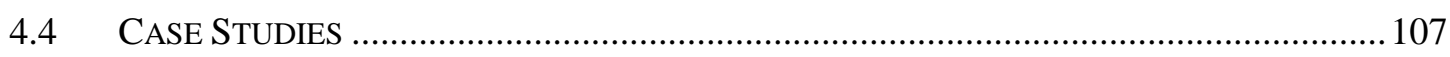

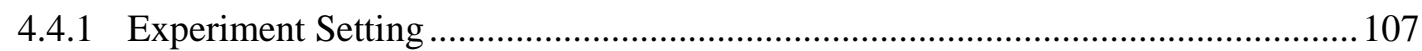

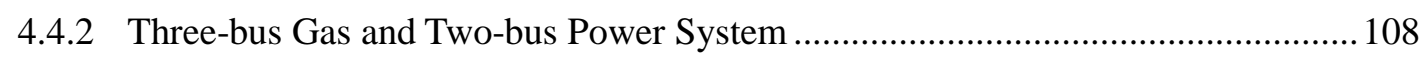

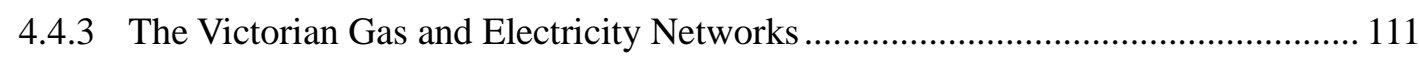

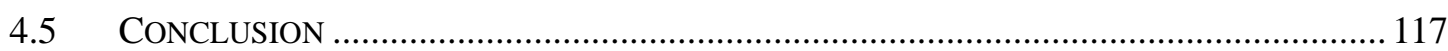

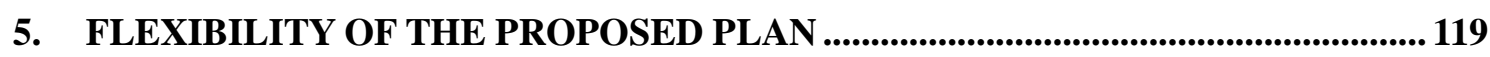

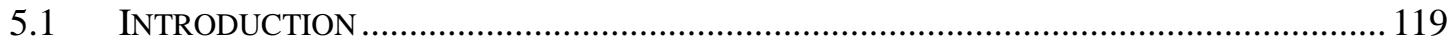

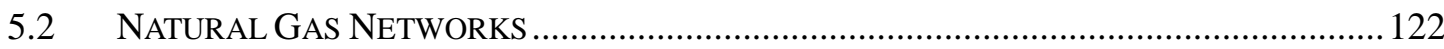

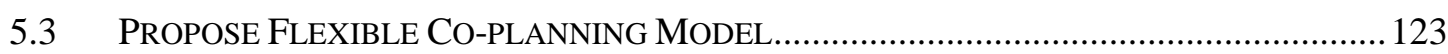

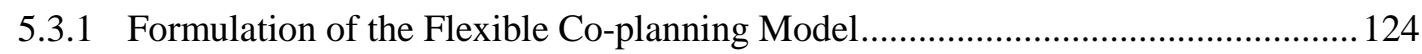

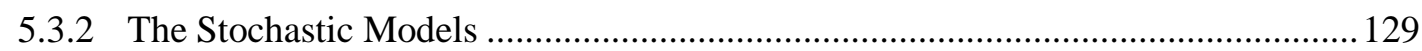

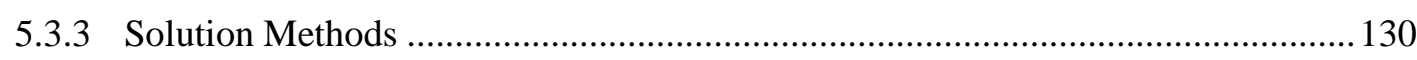

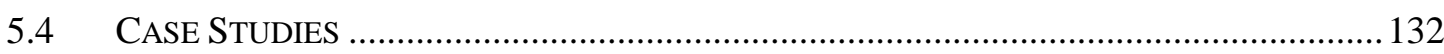

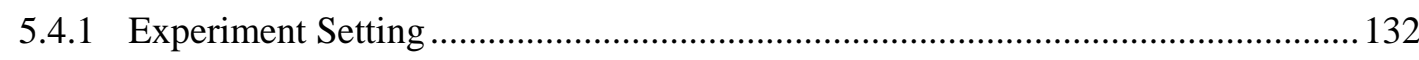


5.4.2 Computational Efficiency 133

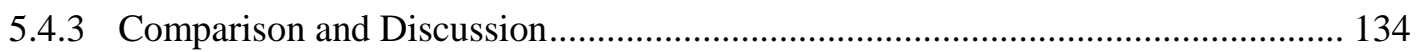

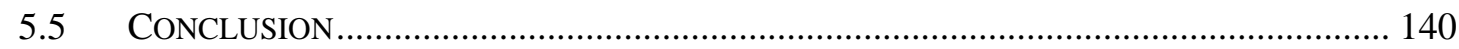

6. ENERGY NETWORK'S VULNERABILITY TO EXTREME EVENTS ................ 143

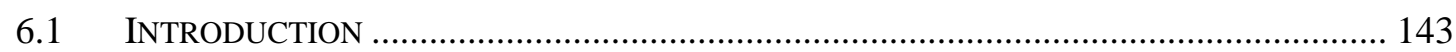

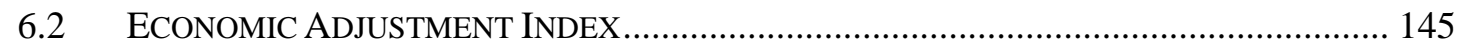

6.2.1 Conventional Risk Value Calculation ................................................................. 145

6.2.2 Economic Adjustment Index and Adjusted Risk Value............................................ 146

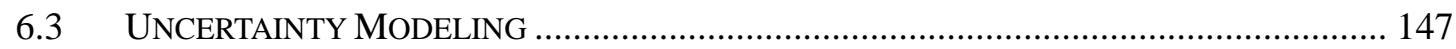

6.3.1 Wind Power Uncertainty Modeling ….................................................................. 147

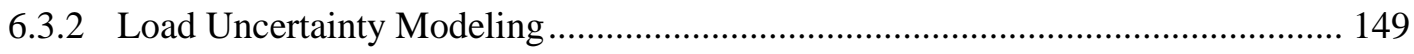

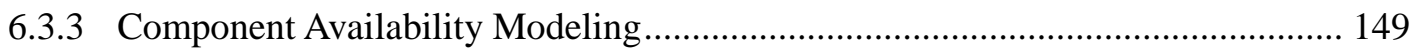

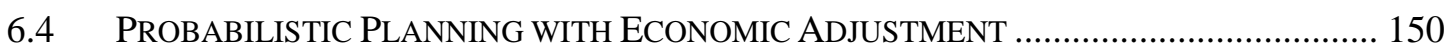

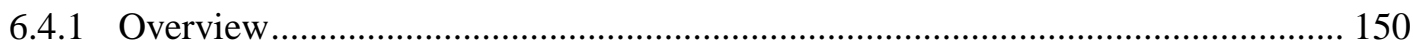

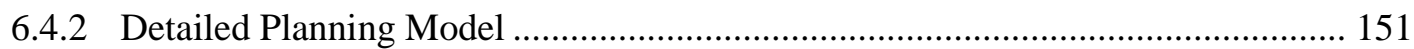

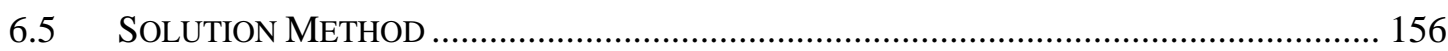

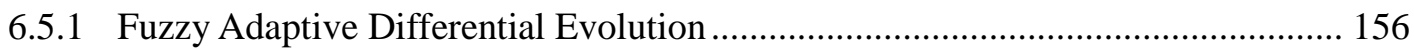

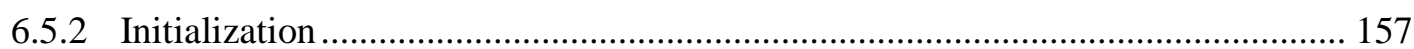

6.5.3 Fuzzy Adaptive Control Parameter Tuning........................................................ 157

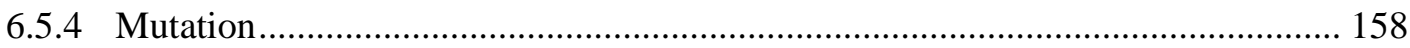

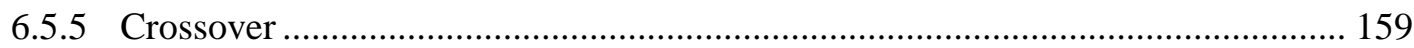

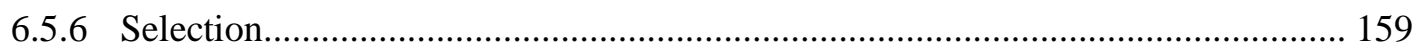

6.5.7 Encoding the Proposed Model into FADE............................................................ 159

6.5.8 Parallel Implementation of FADE-based Transmission Network Planning............ 159

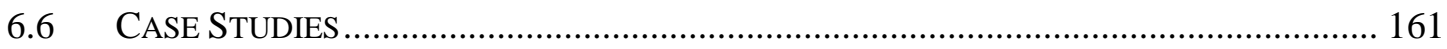

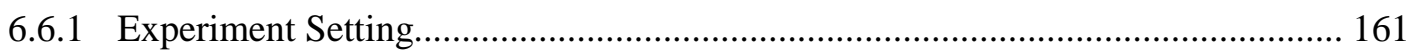

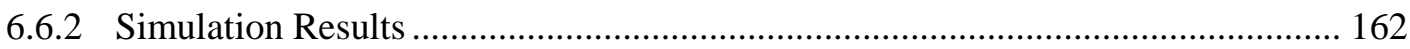

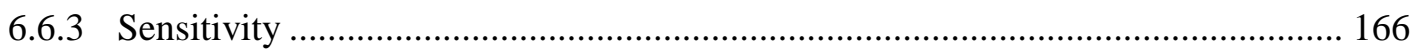

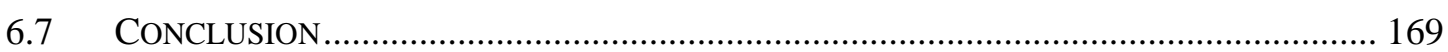

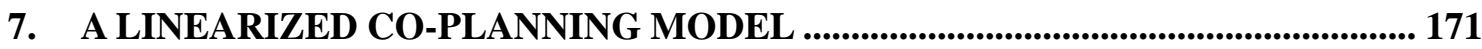

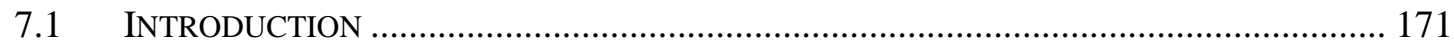

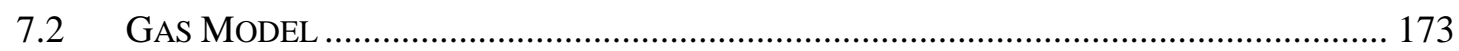

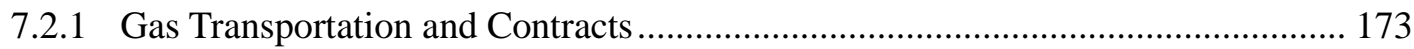

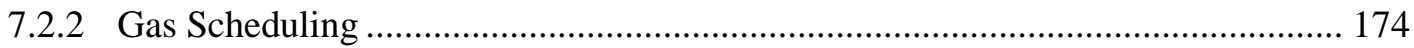

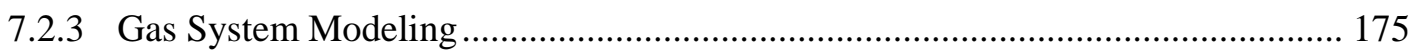

7.3 FORMULATION OF OUR EXPANSION CO-PLANNING MODEL.................................... 177

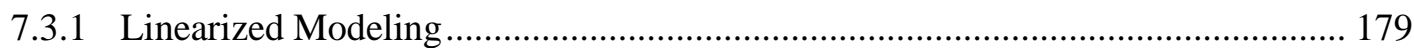

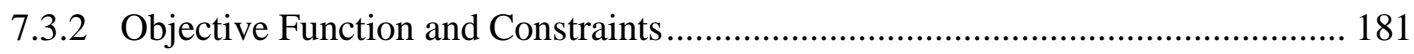

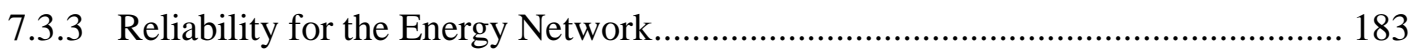

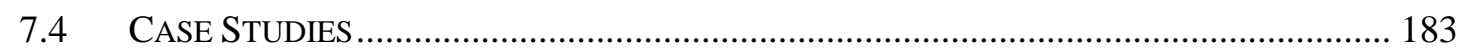

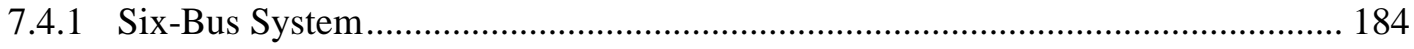

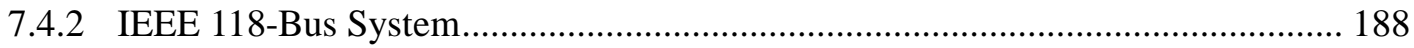

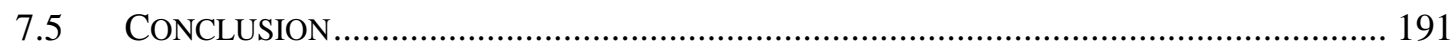




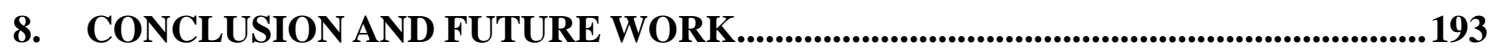

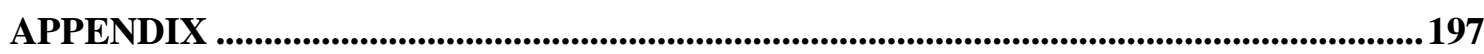

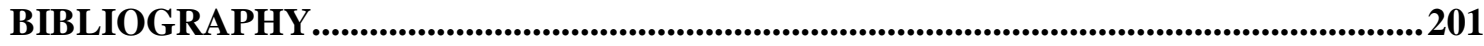




\section{LIST OF FIGURES}

Fig. 1-1 Structure of power system planning

Fig. 2-1 A typical set of ratings and membership corresponding to different qualitative judgments.

Fig. 2-2 Dynamic gas flow model.............................................................................. 53

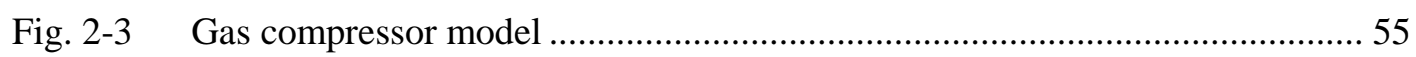

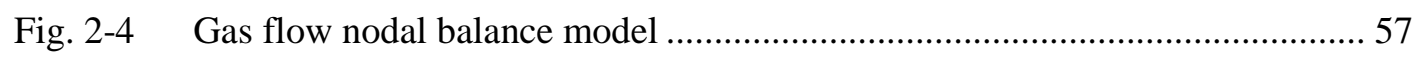

Fig. 2-5 An example of using nodal balance to calculate gas flows ............................. 57

Fig. 2-6 An example of integrated natural gas and power systems ................................6 60

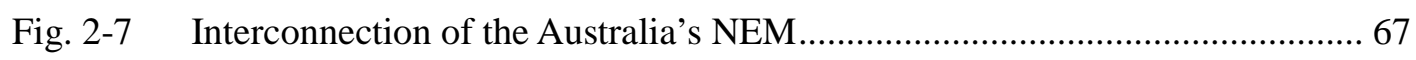

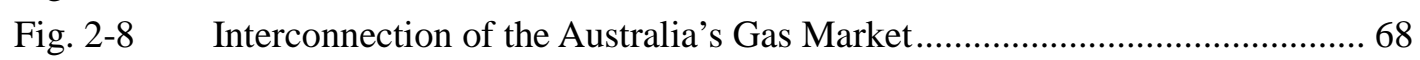

Fig. 2-9 An example of gas scheduling in spot markets ........................................... 70

Fig. 3-1 Multi-energy carrier of gas and power systems …........................................ 75

Fig. 3-2 A generalized condition description approach of a component....................... 79

Fig. 3-3 Proposed state-space diagram for gas storage ............................................ 80

Fig. 3-4 Experiments with different trails for the capital investment cost................... 86

Fig. 3-5 The Pareto optimality solutions for three cases with objectives of EENS and

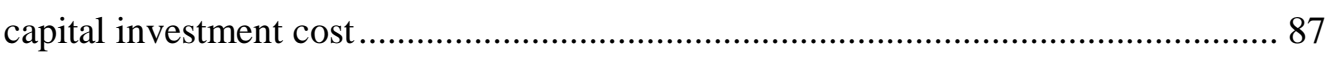

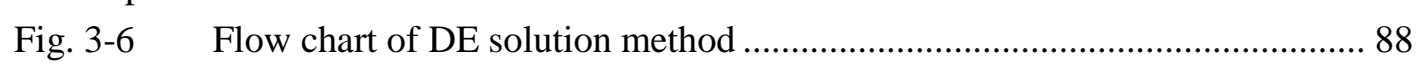

Fig. 3-7 The summed working volume of gas in gas networks for cases 2 and 3 (note

that positive values mean gas to be extracted, negative values mean gas to be stored)88

Fig. 3-8 The chosen expansion plans in power networks for three cases .................... 89

Fig. 3-9 The chosen expansion plans in gas networks for three cases .......................... 90

Fig. 3-10 Sensitivity analysis with four parameters for two cases................................ 92

Fig. 4-1 Proposed approach for natural gas and power systems expansion

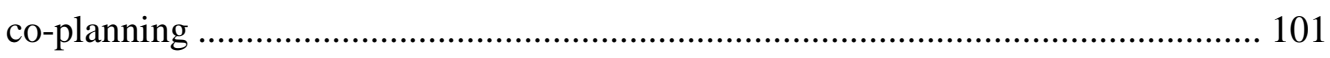

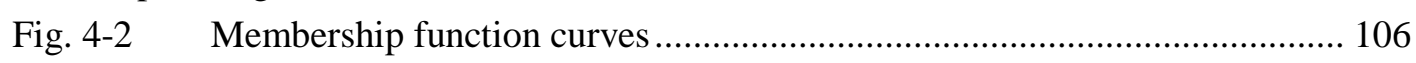

Fig. 4-3 A three-bus gas and two-bus power systems ............................................. 109

Fig. 4-4 Linepack simulation results for EP and ECP in scenario 3 ...........................110

Fig. 4-5 Linepack variations for EP and ECP on peak demand day ...........................112

Fig. 4-6 Summed total GPG gas demand for EP and ECP in four scenarios on peak

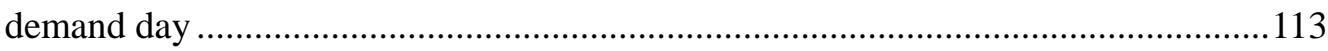

Fig. 4-7 Comparing the chosen alternatives for separated gas and power system

planning versus gas and power system co-planning ................................................116

Fig. 5-1 Proposed flexible co-planning method........................................................ 124

Fig. 5-2 Concepts of the life-cycle of capital assets and discounted cash flow ......... 125

Fig. 5-3 Flow chart of the proposed HDDE algorithm ............................................. 131

Fig. 5-4 The base case of the combined gas and power systems ............................... 132

Fig. 5-5 Convergence of 2000 iterations for two cases............................................ 134

Fig. 5-6 Comparison of the power system for two cases ........................................... 137

Fig. 5-7 Comparison of the flexible co-planning and power system planning ........... 138 


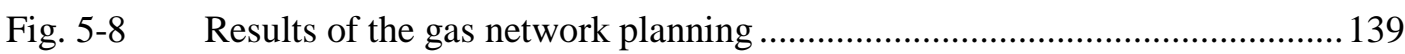

Fig. 6-1 Parallel model for the FADE-based transmission planning ............................161

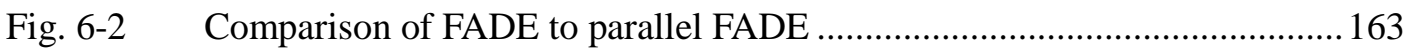

Fig. 6-3 Comparison of convergence of two cases when EA index is 10....................163

Fig. 6-4 Probability distribution of operating costs with initial setting for case $2 \ldots . .164$

Fig. 6-5 CDFs of adjusted risk value to extreme events with various EA indices for

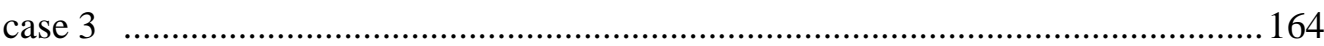

Fig. 6-6 The overall cost against various EA indices with different peak loads; and probability of risk to EEs against various EA indices with peak load 6700 MW......167

Fig. 6-7 The overall cost against various EA indices with different wind power cost coefficients; and probability of risk to EEs against various EA indices with cost coefficients 14, 42 and -98 ...

Fig. 6-8 The overall cost against various EA indices with different peak loads; and probability of risk to EEs against various EA indices with total wind power capacity $1200 \mathrm{MW}$, all WPFs have equal capacities. 168

Fig. 6-9 The overall cost against various EA indices with different wind power cost coefficients; and probability of risk to EEs against various EA indices with all wind power capacity located at bus 166 168

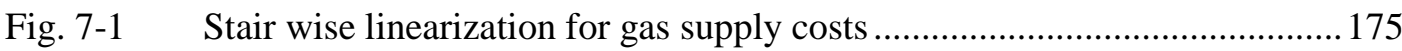

Fig. 7-2 Proposed iterative expansion co-planning framework ...................................178

Fig. 7-3 Operation and expansion capital costs in the electricity sector....................... 185

Fig. 7-4 Total costs in gas and electricity sectors for cases 3 and 4 .......................... 186

Fig. 7-5 Operation and expansion capital costs in the gas sector .............................187

Fig. 7-6 Operation and expansion capital costs in the electricity sector...................... 187

Fig. 7-7 Objective and literation number with various linear sections.........................189

Fig. 7-8 Total costs and energy losses in the planning period for cases 3 and 4 .........189 


\section{LIST OF TABLES}

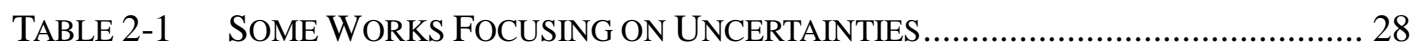

TABLE 2-2 SOME WORKS FOCUSING ON RELIABILITY/SECURITY ................................. 36

TABLE 2-3 SOME WORKS FOCUSING ON DEREGULATE ELECTRICITY MARKETS............ 42

TABLE 2-4 SOME WORKS FOCUSING ON INTEGRATING RENEWABLE ENERGY ................ 44

TABLE 2-5 SOME WORKS FOCUSING ON COORDINATED PLANNING ............................... 46

TABle 2-6 SOME WORKS FoCUSING ON PLANNING WiTH OTHER CONSIDERATIONS.... 47

TABLE 2-7 FUNDAMENTALS IN GAS NETWORK MODELLING............................................ 52

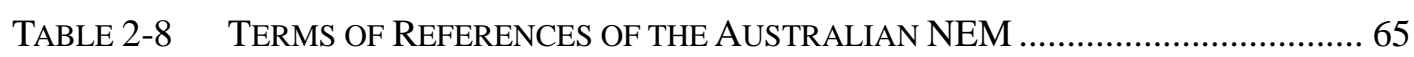

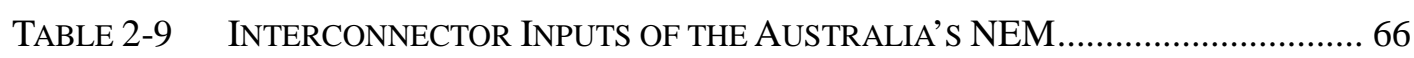

TABLE 3-1 PARAMETERS OF CANDIDATE PLANS .............................................................. 84

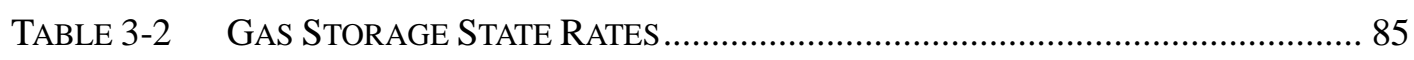

TABLE 3-3 EXISTING GAS PIPELINE PARAMETERS ...................................................... 85

TABLE 3-4 GAS STUDY PARAMETERS AT NODE................................................................ 85

TABlE 3-5 Distance OF NEWLy Found Gas RESERVOIR TO NETWORK NODES........... 86

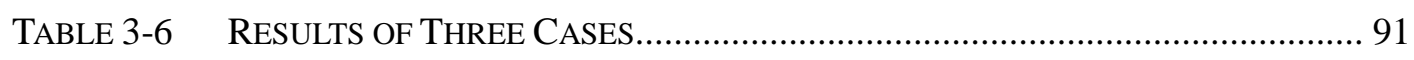

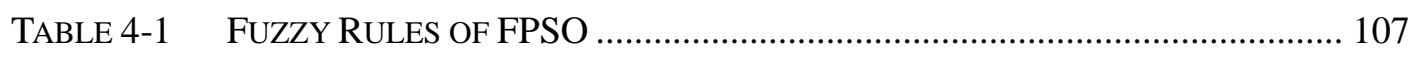

TABLE 4-2 GAS LOAD (TJ/HOUR) AND ELECTRICITY LOAD (MW) OVER ONE DAY FOR

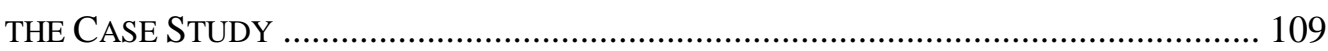

TABle 4-3 COST AND BENEFIT FOR EP AND ECP UNDER THREE SCENARIOS ON

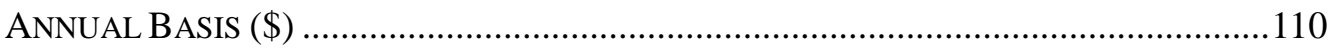

TABLE 4-4 REgRETS FOR EP AND ECP IN FOUR SCENARIOS …......................................117

TABle 4-5 Results OF THE Best Alternatives FOR EP AND ECP (MONETARY

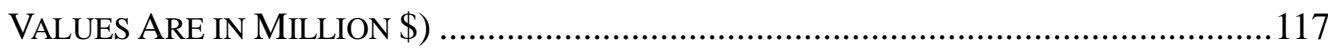

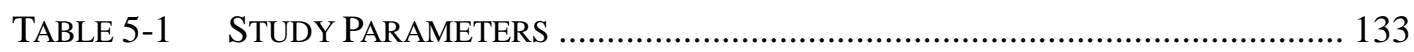

TABLE 5-2 The EXISTING GAS NETWORK PARAMETERS ............................................ 133

TABLE 5-3 RESULTS FOR EXPANSION CO-PLANNING ..................................................... 135

Table 5-4 Adaptation Costs (Million\$) FOR CASE 1 With NeW Generation

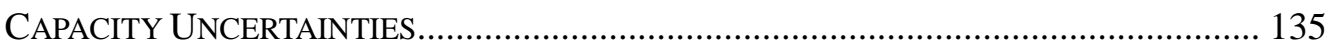

TABle 5-5 COMPare the Total COST (Million\$) WiTH ECP Plan FOR FlEXIBILITY

UNDER UNCERTAINTIES OF NEW GENERATION CAPACITY ENTRY ….......................... 135

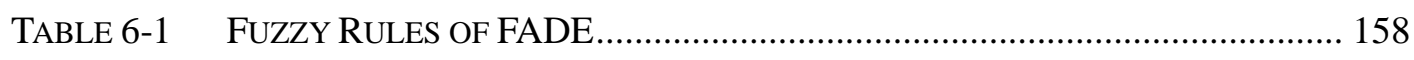

TABle 6-2 Results COMPARISON fOR CASES 1 AND 2 WITH INITIAL PARAMETERS

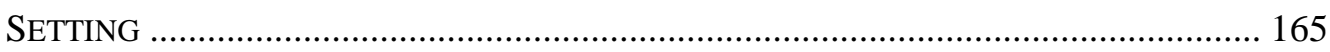

TABle 6-3 Plans for Two CASES with Different Economic AdJustment

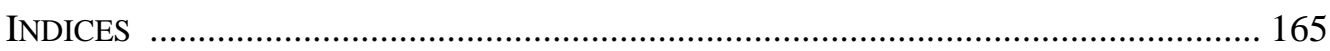

TABle 6-4 Detailed Results Compared to System With 0 MW Wind PoWer

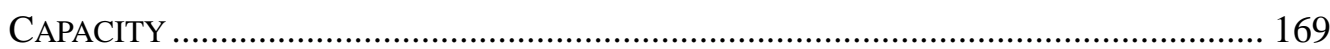

TABLE 7-1 DETAILED EXPANSION PlANS FOR CASES 3 AND 4.................................... 190 



\section{NOMENCLATURE FOR ABBREVIATIONS}

\begin{tabular}{|c|c|}
\hline $\mathrm{AC}$ & Alternating current \\
\hline ACP & Annual capital payment \\
\hline ADLC & Average duration for each load curtailment \\
\hline AEMO & Australian energy market operator \\
\hline $\mathrm{CDF}$ & Cumulative distribution function \\
\hline CRF & Capital recovery factor \\
\hline $\mathrm{CS}$ & Compressor station \\
\hline DC & Direct current \\
\hline $\mathrm{DE}$ & Differential evolution \\
\hline DG & Distributed generation \\
\hline DISCOs & Distribution companies \\
\hline DSM & Demand-side management \\
\hline EA & Economic adjustment \\
\hline ECP & Expansion co-planning \\
\hline EDLC & Expected duration of load curtailment \\
\hline EEs & Extreme events \\
\hline EENS & Expected energy not supplied \\
\hline EFLC & Expected frequency of load curtailment \\
\hline EIR & Energy index of reliability \\
\hline EP & Expansion planning \\
\hline EUE & Expected unserved energy \\
\hline FACTs & Flexible alternating current transmission system \\
\hline FADE & Fuzzy adaptive differential evolution \\
\hline GA & Genetic algorithm \\
\hline GENCOs & Generation companies \\
\hline GPG & Gas-fired power generation \\
\hline HDDE & Historical driven differential evolution \\
\hline ISO & Independent system operator \\
\hline KKT & Karush-Kuhn-Tucker \\
\hline LNG & Liquefied natural gas \\
\hline LOEE & Loss of energy expectation \\
\hline LOLC & Loss of load cost \\
\hline LOLE & Loss of load expectation \\
\hline LOLP & Loss of load probability \\
\hline LP & Line-pack \\
\hline MC & Monte Carlo \\
\hline MNSP & Market network service provider \\
\hline MTTF & Mean time to failure \\
\hline MTTR & Mean time to repair \\
\hline NERC & North American Electric Reliability Coporation \\
\hline
\end{tabular}




\begin{tabular}{|l|l|}
\hline NEM & National electricity market \\
\hline NPV & Net present value \\
\hline NSW & New South Wales \\
\hline OPF & Optimal power flow \\
\hline PDF & Probability density function \\
\hline PLC & Probability of load curtailment \\
\hline POE & Probability of exceedance \\
\hline PSO & Particle swam optimization \\
\hline QLD & Queensland \\
\hline RRN & Regional reference node \\
\hline SA & South Australia \\
\hline SAIDI & System average interruption duration index \\
\hline SAIFI & System average interruption frequency index \\
\hline SIS & Sequential importance sampling \\
\hline STTM & Short-term trading market \\
\hline TAS & Tasmania \\
\hline TEP & Transmission expansion planning \\
\hline ToP & Take-or-pay \\
\hline TRANSCOs & Transmission companies \\
\hline UC & Unit commitment \\
\hline UGS & Underground gas storage \\
\hline WPFs & Wind power farms \\
\hline VCR & Value of customer reliability \\
\hline VIC & Victoria \\
\hline
\end{tabular}




\section{LiST OF PUBLICATIONS INCLUDED AS PART}

\section{OF THIS THESIS}

The following publications as the major Ph.D. research results of this candidate are included as part of this thesis.

[P1] K. Meng, Z.Y. Dong, Y. Zheng, J. Qiu and K. P. Wong, “Optimal allocation of ESS in distribution systems considering wind power uncertainties", Proc. 2012 the International Conference on Power System Control, Operations and Management (APSCOM), Hong Kong, Jul. 2012.

[P2] F. J. Luo, Z. Y. Dong, Y. Y. Chen, E. Pozorski, J. Qiu, Y. Zheng, Y. Xu and K. Meng, “Constructing the power cloud data centre to deliver multi-layer services for smart grid”, Proc. 2012 APSCOM, Hong Kong, Jul. 2012.

[P3] J. Qiu, Z. Y. Dong, K. Meng, Y. Zheng, Y. Y. Chen and H. Q. Tian "Risk sharing strategy for minimizing imbalance costs of wind power forecast errors”, Proc. 2013 IEEE Power and Energy Society (PES) General Meeting, Vancouver, Canada, Jul. 2013.

[P4] J. Qiu, Z. Y. Dong, G. Chen, H. Q. Tian, Y. Y. Chen, and F. J. Luo, "Expansion co-planning with uncertainties in a coupled energy market”, Australian Universities Power Engineering Conference (AUPEC2013), Tasmania, accepted to be published.

[P5] H. Q. Tian, Z. Y. Dong, J. Qiu, G. Chen, Y. Y. Chen, and W. F. Yao, “A new reliability criterion for energy market expansion planning”, AUPEC 2013, Tasmania accepted to be published.

[P6] J. Qiu, Z. Y. Dong, H. Q. Tian and Y. Zheng, “Apply theories of motivation to project-based power planning entities”, International Conference on Management Innovation and Business Innovation (ICMIBI) 2013, Singapore, accepted to be published. 
[P7] Y. Zheng, Z. Y. Dong, F. J. Luo K. Meng, J. Qiu and K. P. Wong "Optimal allocation of energy storage system for risk mitigation of DISCOs with high renewable penetrations,” IEEE Trans. Power Systems, vol. 29, no. 1, pp. 212-220, Jan. 2014.

[P8] Y. Zheng, Z. Y. Dong, Y. Xu, K. Meng, J. H. Zhao and J. Qiu "Electric vehicle battery charging/swap stations in distribution systems: comparison study and optimal planning,” IEEE Trans. Power Systems, vol. 29, no. 1, pp. 221-229, Jan. 2014.

[P9] J. Qiu, Z. Y. Dong, J. H. Zhao, K. Meng, H. Q. Tian and K. P. Wong “Expansion co-planning with uncertainties in a coupled energy market”, accepted by 2014 IEEE PES General Meeting, Washington D. C., USA, Jul. 2014.

[P10] J. Qiu, Z. Y. Dong, J. H. Zhao, K. Meng, Y. Zheng and D. Hill, "Expansion planning of integrated gas and power markets in a coupled energy market,” accepted for submitting full paper to the special issue on low carbon economy on IEEE Trans. Power Systems, 2014.

[P11] F. J. Luo, J. H. Zhao, J. Qiu, J. Foster, Y. Y. Peng and Z. Y. Dong, “Assessing the transmission expansion cost with distributed generation: an Australian case study," accepted by IEEE Trans. Smart Grid, 2014.

In addition, the candidate has submitted ten manuscripts for publication, which are currently under review. These submitted manuscripts are listed below.

[SP1] Fengji Luo, Z.Y. Dong, Y.Y. Chen, K. Meng, J. Qiu, J.H. Zhao, Eric Pozorski, and K.P. Wong, "Cloud computing infrastructure for next-generation power system: conception, prospective, and applications, ” IEEE Trans. Industrial Informatics, current under $2^{\text {nd }}$ review.

[SP2] Y. Y. Chen, Z. Y. Dong, F. J. Luo, K. Meng, J. Qiu and K. P. Wong, “A multi-constrained optimal power flow method with discrete control variables”, IEEE Trans. Power Systems, submitted. 
[SP3] Y. Y. Chen, Z. Y. Dong, F. J. Luo, K. Meng, J. Qiu and K. P. Wong, “A collector system layout optimization model for large-scale offshore wind farms”, IEEE Trans. Sustainable Energy, submitted.

[SP4] J. Qiu, Z. Y. Dong, J. H. Zhao, Y. Xu and Y. Zheng, "Multi-stage flexible expansion co-planning with uncertainties in a combined electricity and gas market,” IEEE Trans. Power Systems, submitted.

[SP5] J. Qiu, Z. Y. Dong, K. Meng, F. J. Luo and K. P. Wong "Coordination of transmission and generation capacity planning in a coupled energy market,” IEEE Trans. Power Systems, submitted.

[SP6] J. Qiu, Z. Y. Dong, J. H. Zhao, K. Meng, Y. Zheng and K. P. Wong "Expansion co-planning considering gas impacts on electricity markets,” IEEE Trans. Power Systems, submitted.

[SP7] J. Qiu, Z. Y. Dong, J. H. Zhao, K. Meng, Y. Zheng and H. Q. Tian "Insurance strategy for minimizing imbalance costs of wind power in real-time markets,” IEEE Trans. Sustainable Energy, current under 2nd review.

[SP8] J. Qiu, Z. Y. Dong, J. H. Zhao, K. Meng, F. J. Luo and K. P. Wong “An economic adjustment approach for probabilistic transmission expansion planning,” IEEE Trans. Power Systems, submitted.

[SP9] J. Qiu, Z. Y. Dong, J. H. Zhao, K. Meng, Y. Zheng and K. P. Wong "Expansion co-planning for shale-gas integration in a combined energy market,” IEEE Trans. Power Systems, submitted.

[SP10] J. Qiu, Z. Y. Dong, J. H. Zhao, K. Meng, Y. Zheng and K. P. Wong "A linear programming approach for expansion co-planning in energy markets,” IEEE Trans. Power Systems, submitted.

I warrant that I have obtained, where necessary, permission from the copyright owners to use any third party copyright material reproduced in the thesis, or to use any of my own published work (e.g. journal chapters) in which the copyright is held by another party (e.g. 
publisher, co-authors). 


\section{ABSTRACT}

Power system planning plays an essential role in maintaining the economic, secure and reliable operations of power systems. Following the deregulation of electricity industry, power system planning encounters many challenges as a result of the advent of various market participants, such as market uncertainties and conflicting objectives. Moreover, due to the growing concerns on climate change around the world, natural gas becomes more economically competitive among traditional fossil fuels, leading to the proliferation of gas-fired power generation (GPG) in the power sector. In a market environment, the access to affordable and reliable gas sources can significantly influence the competitiveness of market participants, and then the power system operations consequently. Therefore, power system planning should integrally take into account the gas infrastructure.

Fuel availability and prices are treated as uncertain inputs in conventional power system planning methods, which usually suffer from inaccurate market signals (e.g. congestion costs) and insufficient knowledge of network weakness. This thesis research focuses on the proposal of an expansion co-planning framework for gas and electricity transmission infrastructure in a combined energy market. The expansion co-planning approach is able to reflect the dynamic, nonlinear and non-convex nature of the integrated gas and electricity systems. In addition to the reliability/security planning criterion, this research aims to enhance the market efficiency of assets through the planning practice, e.g. facilitating competition, alleviating congestion, improving social welfare, minimizing risks, etc.

The proposed expansion co-planning framework can be used to guide the energy industry to form a holistic approach to the strategic planning of future grids including gas and electricity networks, subject to various interacting constraints. It has covered a variety of aspects in planning, including a generalized reliability evaluation method for coupled gas and electricity networks, market timeline mismatch, multi-objectives, tackling interactive constraints, stochastic programming, risk management, energy networks' vulnerability to extreme events 
caused by climate change, and linearization techniques. With regard to planning solution techniques, a range of up-to-date methods have been applied or developed, including differential evolution, decision making analysis with the fuzzy particle swarm optimization, historical driven differential evolution with variance reduction techniques, fuzzy adaptive differential evolution with parallel implementation, linear programming, mixed-integer programming, iterative algorithm, etc.

A number of benchmark test systems have been used to demonstrate the effectiveness of the proposed expansion co-planning approach. Comparative studies to existing approaches in the literature, where applicable, have also been conducted. The real applicability of the proposed approach has been verified by simulation results. 